\title{
HISTÓRIA DO ESPORTE UNIVERSITÁRIO NO BRASIL (1933-1941)
}

HISTORY OF COLLEGE SPORTS IN BRAZIL (1933-1941)

HISTORIA DEL DEPORTE UNIVERSITARIO EN BRASIL (1933-1941)

Vitor Lucas de Faria Pessoa*, Cleber Dias*

Palavras chave

História.

Esportes.

Universidades.

Brasil.
Resumo: 0 objetivo deste trabalho é analisar a história do esporte universitário no Brasil entre 1933 e 1941, período compreendido entre as primeiras iniciativas estudantis para organizações de associações esportivas e o momento em que o Estado assume 0 controle dessas associações. Para isso, consultamos o acervo digital da Hemeroteca da Biblioteca Nacional do Rio de Janeiro, onde identificamos notícias relacionadas ao assunto, publicadas em jornais e revistas de vários estados brasileiros no período. Apesar da contribuição do poder público, o associativismo civil protagonizado pelos próprios estudantes foi um dos principais fatores para o desenvolvimento inicial do esporte universitário no Brasil, ao menos até 1941, quando o Estado se apropria das instituições estudantis que organizavam o esporte universitário no país.
Keywords:

History.

Sports.

Universities.

Brazil.
Abstract: This paper analyzes the history of college sports in Brazil between 1933, when the first student initiatives were taken to organize sports associations, and 1941, when these associations were taken over by the State. We consulted the digital collection of the National Library in Rio de Janeiro and found news related to the topic published in newspapers and magazines of several Brazilian states at the time. Despite the contribution of the State, civil associationism carried out by students themselves was one of the main factors for the early development of college sports in Brazil, at least until 1941, when the State took over student institutions that organized university sports.

Palabras clave: Historia. Deportes. Universidades. Brasil.
Resumen: El objetivo de este trabajo es analizar la historia del deporte universitario en Brasil entre 1933 y 1941, periodo comprendido entre las primeras iniciativas estudiantiles para organizar asociaciones deportivas y el momento en que el Estado asume el control de esas asociaciones. Para ello, consultamos el acervo digital de la Hemeroteca de la Biblioteca Nacional de Rio de Janeiro, donde identificamos noticias relacionadas al asunto publicadas en diarios y revistas de varios estados brasileños en el periodo. A pesar de la contribución del poder público, el asociativismo civil protagonizado por los propios estudiantes fue uno de los principales factores para el desarrollo inicial del deporte universitario en Brasil, al menos hasta 1941, cuando el Estado se apropia de las instituciones estudiantiles que organizaban el deporte universitario en el país.
*Universidade Federal de Minas Gerais. Belo Horizonte, MG, Brasil. E-mail: vitorlfpessoa@ hotmail.com; cleberdiasufmg@gmail.com

Recebido em: 02-05-2018 Aprovado em: 13-03-2019 Publicado em: 18-04-2019

DOI: https://doi.org/10.22456/1982-8918.82512 (c) (i) () Licence 


\section{INTRODUÇÃOO}

O papel de instituições educacionais para o desenvolvimento histórico dos esportes tem sido enfatizado pela bibliografia especializada (MANGAN, 1981; O'HANLON, 1982; SANTOS NETO, 2002). Não obstante, ainda são poucas as pesquisas sobre a história do envolvimento de instituições universitárias e seus estudantes com esportes no Brasil (LINHARES, 2009; STAREPAVO, 2006; STAREPRAVO et al., 2010). Nesse contexto, o objetivo deste artigo é analisar a história do esporte universitário no Brasil entre 1933 e 1941.

Com esse propósito, consultamos o acervo digitalizado da Hemeroteca da Biblioteca Nacional do Rio de Janeiro, onde identificamos centenas de notícias direta ou indiretamente relacionadas ao assunto, publicadas em jornais e revistas de vários estados desde 1905. Neste artigo, porém, analisamos apenas o material relativo ao período entre 1933 e 1941, que coincide com a criação das três primeiras federações estaduais de esporte universitário, além de uma confederação que reuniu todas essas federações e mais grêmios estudantis, centros acadêmicos e associações atléticas de outras regiões.

Mais especificamente, a partir de 1933, registraram-se as primeiras iniciativas para criação de instituições esportivas universitárias no Rio de Janeiro, São Paulo e Minas Gerais, que foram as primeiras regiões brasileiras a terem também universidades propriamente ditas, reunindo, nessa época, pouco mais de $76 \%$ do total de estudantes de nível superior do Brasil (BRASIL, 1950, p. 85-87). 0 ano de 1941, por outro lado, oferece uma data conveniente para delimitar o período que encerra esta análise, na medida em que acontecimentos daquele ano assinalam o fim de uma forma de organização do esporte universitário, marcada, até então, pelo engajamento dos próprios estudantes na criação e direção de associações esportivas. Desse momento em diante, contudo, por meio do decreto-lei no 3.617 , de 15 de setembro de 1941 (BRASIL, 1941), que entre outras providências criou a Confederação Brasileira de Desportos Universitários (CBDU), as entidades esportivas criadas antes pelos estudantes foram substituídas por instituições controladas pelo Estado - totalmente em conformidade ao que se fazia em outras esferas de atuação no período. Era o Estado, em todo o caso, que se tornava o principal agente de regulação, fomento e organização dos esportes universitários.

Apesar do pioneirismo e da relevância da atuação das federações esportivas universitárias do Rio de Janeiro e de São Paulo, acontecimentos de outras partes foram também importantes, dado que em diferentes medidas se articularam com a mobilização estudantil que se desenrolou ao longo da década de 1930 e que tinha ambições de abrangência nacional - embora, na prática, tivesse um escopo mais reduzido. Nesse sentido, a abrangência das nossas análises, bastante confinadas ao Rio de Janeiro e a São Paulo, apenas refletem os limites documentais e históricos do próprio objeto de pesquisa. Acontecimentos de outras regiões foram levados em conta tanto quanto possível.

\section{ESPORTE UNIVERSITÁRIO NO BRASIL, 1933-1941}

A primeira federação de esporte universitário do Brasil foi criada em 1933, no Rio de Janeiro. Foi a Federação Atlética de Estudantes (FAE) (UM GRANDE..., 1933). A entidade foi responsável por organizar vários campeonatos esportivos entre centros acadêmicos e grêmios estudantis do Rio de Janeiro ao longo da década de 1930. Sua sede funcionava na Casa 
do Estudante do Brasil (fundada em 1929). Em 1934, em São Paulo, foi criada a Federação Universitária Paulista de Esportes (FUPE), fundada por meio de uma assembleia que teria reunido representantes de todos os centros acadêmicos de São Paulo (COMO SERÁ..., 1935). Tal como a entidade do Rio de Janeiro, a FUPE foi a instituição responsável por gerir e incentivar todo o esporte universitário em São Paulo ao longo da década de 1930. Por volta de 1938, já existia também uma Federação Universitária Mineira de Esportes (FUME) (SOB O PATROCINIO..., 1938, p. 8), sobre a qual dispomos de menos informações.

Essas federações organizavam competições esportivas regulares de várias modalidades, geralmente utilizando instalações esportivas de clubes. Algumas delas tinham repercussão bastante positiva, sendo frequentemente retratadas pelas imprensas locais como "competições atléticas férteis", eventos de "extraordinário êxito", "lutas esportivas gigantescas e emocionantes" (cf. ATLETISMO, 1934, p. 6; O ESPORTE UNIVERSITÁRIO, 1934, p. 6; OS PAULISTAS..., 1935, p. 4). De modo geral, a relação entre estudantes e imprensa era bastante positiva. Favorecia a situação a atuação de estudantes envolvidos com a direção de entidades esportivas universitárias, como foi o caso de Cid Navajo e José Gomes Talarico, que trabalharam no jornal Correio Paulistano. Além disso, tanto por enxergarem nos esportes um veículo relevante para a educação, quanto por verem nessas práticas boas oportunidades comerciais, havia também certa disposição dos jornais em tomar para si a missão de incentivar e divulgar a prática esportiva, o que beneficiava algumas instituições esportivas, incluindo a de estudantes de ensino superior.

Nesse momento, nenhuma dessas instituições contava com auxílio financeiro regular do Estado ou das universidades. Tal situação, inclusive, frequentemente foi objeto de críticas e reclamações de estudantes ou jornalistas (BAILE UNIVERSITÁRIO..., 1936). Convites para participação em competições esportivas estudantis internacionais, como os VI Jogos Internacionais Universitários, realizados pela União Esportiva Universitária da Hungria, em 1935, em Budapeste, não podiam ser atendidos por simples falta de recursos para custear as despesas (O BRASIL AUSENTE..., 1935).

Como alternativa, uma das maneiras de arrecadar fundos para organização ou participação em competições esportivas era a realização de festas. Federações esportivas universitárias ou associações atléticas podiam, inclusive, dispor de "departamentos sociais" especialmente dedicados à organização de festas e bailes. Uma alternativa era solicitar apoio financeiro eventual a autoridades políticas. Nesse sentido, é notável a relativa facilidade com que estudantes tinham acesso a reitores, embaixadores, prefeitos, secretários de Estado, governadores, ministros e até ao presidente da República, como veremos em alguns exemplos mais adiante. Naquele contexto, estudantes de cursos superiores, em sua grande maioria, eram filhos das famílias das elites econômicas e políticas. Em 1940, quando 67\% da população brasileira era analfabeta, menos de 1,5\% dos que recebiam alguma instrução escolar estavam no ensino superior (BRASIL, 1950, p. 1 e 87). O caráter elitista dessas instituições as tornava espaços importantes para articulação política, especialmente no período analisado aqui, quando a juventude seria vista como pedra angular para o futuro da nação.

Assim, o início do processo de organização institucional de esportes universitários no Brasil, do qual a fundação de federações esportivas universitárias estaduais é um dos principais elementos, aparece como o desdobramento de ações mais dispersas e um pouco menos organizadas desenvolvidas desde antes. Pois antes ainda de se estruturarem federações, 0 
esporte universitário era já organizado no interior dos grêmios estudantis, centros acadêmicos e associações atléticas. A realização de competições esportivas entre equipes de diferentes faculdades, seguidas, em alguns casos, pela criação de federações estaduais que tentavam congregar equipes esportivas de estudantes antes dispersas, facilitou o paulatino surgimento de um circuito nacional de esportes universitários, que deve ser visto como um esforço deliberado para a articulação e sistematização de competições locais e interestaduais que já aconteciam desde antes, só que de maneira irregular. Federações responsáveis pela organização de competições esportivas entre estudantes de diferentes regiões foram o resultado da realização e da iniciativa dos próprios estudantes, que, por meio de artigos em jornais ou declarações à imprensa, explicitamente enfatizaram sua ambição de criar um espaço para articulações e intercâmbios estudantis. É nesse sentido que o surgimento de um circuito nacional de esportes universitários aparece como consequência de um esforço deliberado dos próprios estudantes.

É a partir do momento em que são criadas federações universitárias que o esporte universitário toma proporções propriamente nacionais, apesar das suas discrepâncias regionais - pois havia mesmo uma heterogeneidade regional nos níveis de organização e desenvolvimento esportivo em instituições de ensino superior nos diferentes estados. De todo modo, dos meados da década de 1930 em diante, nota-se uma ampliação do engajamento em favor das práticas esportivas dentro das instituições brasileiras de ensino superior. A partir desse momento, aumentaram a abrangência e o alcance geográfico das competições esportivas universitárias, bem como sua regularidade. A criação das primeiras federações estaduais foi certamente um dos facilitadores desse processo, uma vez que ampliaram oportunidades de intercâmbio esportivo dentro de uma mesma cidade, facilitando também, pouco depois, confrontos esportivos interestaduais.

A FUPE cumpriu um papel importante nesse processo, especialmente a partir do momento em que organizou, em 1935, a I Olimpíada Universitária Brasileira, cujo objetivo, segundo divulgou o jornal Correio de São Paulo, era promover "aproximação mais intensa dos estudantes dos cursos superiores" (A 1 OLYMPIADA..., 1934, p. 4). Cerca de 500 estudantes do Rio de Janeiro, São Paulo, Rio Grande do Sul, Minas Gerais, Paraná, Bahia e Pernambuco participaram das competições de tênis, polo aquático, basquete, esgrima, remo, natação, atletismo e futebol, realizadas entre o fim de março e o começo de abril daquele ano. 0 evento contou com o apoio de importantes figuras políticas do governo de São Paulo, como o secretário da educação, Cantídio de Moura Campos, que decretou "feriado olímpico" no estado, suspendendo as aulas em todos os estabelecimentos de ensino superior de São Paulo (OS FLUMINENSES..., 1935). Em retribuição ao apoio, dirigentes da FUPE homenagearam o secretário após o término das competições, presenteando-Ihe, em seu gabinete, com uma medalha de prata. $O$ secretário teria se comovido, agradecendo e prometendo trabalhar para o engrandecimento da FUPE e da campanha de difusão do esporte universitário ( $A$ FEDERAÇÃO..., 1935). De fato, confirmando expectativas dos organizadores, o evento pareceu ter servido bem aos propósitos de disseminar a prática de esportes entre estudantes, além de funcionar como espaço privilegiado para intercâmbios acadêmicos.

Pouco mais de três anos depois, entre 16 e 24 de julho de 1938, realizou-se, em Belo Horizonte, por iniciativa da FUME, os I Jogos Universitários de Minas Gerais. 0 evento não apenas foi apoiado pelo governo estadual, como foi também "tornado oficial", isto é, assimilado como oferta e responsabilidade do poder público estadual. Na abertura do evento, que se 
realizou com um grande desfile de atletas-estudantes, estiveram presentes várias autoridades políticas de Minas Gerais, além do presidente da República. Aproximadamente 600 estudantes de 22 escolas superiores de Minas Gerais, São Paulo e Rio de Janeiro participaram das competições de futebol, basquete, vôlei, atletismo, natação e tênis que se seguiram naqueles dias. A justificativa formal que se apresentava para a iniciativa era a de acentuar intercâmbios estudantis capazes de fomentar 0 ambiente cultural brasileiro. Desde logo havia a ambição dos estudantes de discutir, durante as competições, os planos para uma nova "olimpíada universitária brasileira" (SOB O PATROCINIO..., 1938, p. 8).

Em 1939, entre os dias 10 e 17 de dezembro, confirmando expectativas dos que estiveram envolvidos com as competições dos dois anos anteriores, em São Paulo e em Belo Horizonte, realizou-se a II Olimpíada Universitária Brasileira, novamente em São Paulo, apesar dos dirigentes da FUPE terem apelado, sem sucesso, para que federações ou grêmios estudantis da Bahia, do Rio de Janeiro e de Minas Gerais realizassem a competição (ESPORTE UNIVERSITÁRIO, 1937). Uma das consequências mais importantes da ll Olimpíada Universitária foi a criação de uma instituição de caráter nacional, destinada à coordenação de diferentes federações esportivas universitárias estaduais - algo cuja idealização parece ter se iniciado no ano anterior, durante plenárias de um congresso estudantil realizado no Rio de Janeiro (UMA ASPIRAÇÃO..., 1938). A realização prática dessas aspirações, porém, aconteceu em agosto de 1939, durante o Congresso Universitário de Esportes, realizado solenemente no Palácio Campos Elíseos, sob patrocínio da Presidência da República e do interventor federal em São Paulo, Adhemar de Barros, como parte dos preparativos da II Olimpíada Universitária, que logo se iniciaria (em dezembro daquele ano). Na ocasião, foi fundada a Confederação Universitária Brasileira de Esportes (CUBE), que teria sede em São Paulo e a pretensão de centralizar toda a organização do esporte universitário do país.

De certo modo, o crescimento do engajamento com esportes universitários era resultado do próprio crescimento da mobilização estudantil ao longo da segunda metade da década de 1930. Nessa época, os estudantes desencadearam uma série de iniciativas para a consolidação nacional da organização estudantil. Uma das mais importantes foi a criação da União Nacional dos Estudantes (UNE), em 1937, que era uma espécie de evolução ou desdobramento do Conselho Nacional do Estudante (criado em 1935).

Afora a própria mobilização dos estudantes, cujas iniciativas conseguiam envolver mais de uma centena de instituições estudantis espalhadas por todo o país, o contexto político da época é outro fator muito importante nesse processo. Com efeito, o crescimento da mobilização estudantil coincide com o crescimento da intervenção governamental em várias esferas de atuação, incluindo o associativismo estudantil. Em diversas ocasiões, autoridades e lideranças políticas do governo deixaram bastante claro que estavam "interessados" nos assuntos estudantis (MAIS UMA SESSÃO..., 1935, p. 3). Na verdade, a própria criação da UNE teria sido estimulada pelo Estado (DULLES, 1984). Por outro lado, fosse por pressão ou por vontade própria, lideranças estudantis colaboraram com ações do governo. A explícita proibição de discussão de temas políticos em encontros estudantis a partir de 1937 é uma indicação das pressões que cercavam as organizações estudantis (CONSELHO NACIONAL DE ESTUDANTES, 1937). Além disso, ao menos desde 1937, precisamente no momento em que a mobilização estudantil parecia se intensificar, ao mesmo tempo em que os esforços do governo federal para centralização do poder também se acentuavam, decisões de plenárias 
de encontros estudantis eram apresentadas a autoridades políticas (SERÁ PRECISO..., 1940). Daí em diante, o apoio financeiro a encontros estudantis seria constante, bem como a presença de prefeitos, interventores estaduais, ministros e até do presidente.

Diversas crises políticas ao longo da década de 1930 (Revolução Constitucionalista, Levantes Comunistas, rebeliões de soldados, a criação da Aliança Nacional Libertadora e greve de trabalhadores) acabaram servindo de pretexto para um esforço governamental mais organizado em favor da tentativa de disciplinar comportamentos. Ao lado dos trabalhadores, a juventude ou a "mocidade", como se dizia na época, esteve entre os grupos mais privilegiados dessa nova atuação política do Estado. Em 1938, Francisco Campos, Ministro da Justiça e um dos mais importantes ideólogos do Estado Novo, sugeriu a criação de uma "Organização Nacional da Juventude", de âmbito nacional e de caráter paramilitar, inspirada em iniciativas semelhantes da Alemanha nazista e da Itália fascista. De acordo com a proposta inicial de Francisco Campos, essa ampla organização deveria dirigir todas as instituições de jovens do país. A proposta, contudo, encontrou oposição entre membros do próprio governo, o que inviabilizou sua efetivação. Em seu lugar, criou-se, em 1940, a "Juventude Brasileira", sem traços militares e voltada apenas para o cultivo de sentimentos de patriotismo (BOMENY, 1999).

Em última instância, iniciativas desse tipo tinham por fim criar e difundir uma utopia de unidade, que pretendia diluir divergências (regionais ou políticas) e impor princípios uniformes de disciplina e pensamento. $O$ discurso de Francisco Campos durante a cerimônia da queima das bandeiras estaduais, em novembro de 1937, é bastante revelador nesse sentido - tanto pelas palavras quanto pelo próprio ritual de queimar bandeiras estaduais. Segundo palavras dele, "o Brasil é uma só pátria e não há lugar para outro pensamento que não seja o pensamento do Brasil" (PARADA, 2009, p. 35). O sentido geral do que se pretendia, portanto, era a primazia do consenso, em detrimento de quaisquer possibilidades de dissensos.

Uma vez que parte importante dos fundamentos ideológicos que justificavam as ações governamentais do Estado Novo conjugava preocupações com a juventude e com a difusão moral de um civismo nacionalista a ser edificado ao redor de um só ideal, além de questões ligadas à eugenia, ao fortalecimento da raça e à preparação militar de futuros soldados, a intervenção nos esportes acabou por se tornar um elemento fundamental dessas concepções, que já se anunciavam desde antes. Durante o Estado Novo, ações governamentais ligadas à Educação Física e aos esportes estiveram mesmo em primeiro plano (HORTA, 2012; PARADA, 2009). Nesse período, o governo esteve deliberadamente empenhado em assumir o controle sobre a organização dos esportes.

Alguns estudantes logo começaram a se envolver ativamente nesse processo. Em certa medida, o controle estatal das instituições esportivas estudantis, cujas primeiras iniciativas começaram por volta de 1937 e se concretizaram em 1941, com o decreto-lei que criou a CBDU, que substitui a antiga CUBE, foi uma demanda dos próprios estudantes, que além de eventuais afinidades ideológicas com os motivos pelos quais o Estado pretendia assumir o controle dos esportes, pareciam enxergar aí vantagens mais imediatas. A expectativa de obter "auxílio moral e material do governo" foi muitas vezes anunciada explicitamente como motivação para apoiar a "oficialização do esporte universitário" - que era a forma como se falava do processo de controle estatal das associações esportivas universitárias. Nesse sentido, discursos sobre "intercâmbio acadêmico", "cooperação intelectual" e "congraçamento da classe estudantil" (cf. A 1 OLYMPIADA..., 1934, p. 4; SOB O PATROCINIO..., 1938, p. 
8), que marcaram justificativas declaradas de competições esportivas universitárias até os meados da década de 1930, aproximadamente, logo começaram a ser substituídos por uma retórica que afirmava tais ocasiões como oportunidades ótimas para a "disciplina do espírito de sacrifício", para a "congregação da raça para a felicidade da pátria" ou para a "reafirmação da grandeza da nacionalidade" (cf. A MOCIDADE UNIVERSITÁRIA, 1941, p. 14; COLLEGAS DE TODO O BRASIL.., 1939, p. 8), inteiramente de acordo com a gramática e o ideário que orientava as ações do Estado Novo.

As linhas gerais do decreto-lei que submeteu a organização esportiva universitária ao controle do Estado apenas reproduziu um anteprojeto elaborado antes pelos próprios estudantes, já visando à "oficialização" da CUBE. Esse anteprojeto foi discutido em assembleias estudantis ao menos três vezes entre 1939 e 1941. Em 1940, um ano antes, portanto, da promulgação do tal decreto-lei, seriam quatro os pontos que interessariam aos universitários nesse processo, segundo Cid Navajas, secretário-geral da FUPE: 1) a necessidade de licenças para o universitário participar de campeonatos de outras entidades esportivas que não fossem estudantis; 2) a mudança do nome da Confederação Universitária Brasileira de Esportes para Confederação Brasileira de Desportos Universitários; 3) a mudança da sede da Confederação de São Paulo para o Rio de Janeiro; 4) o auxílio moral e material do governo (SERÁ PRECISO..., 1940).

Apesar desse protagonismo estudantil, a forma como vários jornais repercutiram a decisão tendeu a apontar, recorrentemente, para o presidente Getulio Vargas e Gustavo Capanema, o onipresente Ministro de Educação e Saúde da época, como os únicos e principais responsáveis pela medida. A censura a que os jornais estavam submetidos nesse período deve ter condicionado o modo de noticiar tais acontecimentos. Implícita ou explicitamente, órgãos de censura, como o Departamento de Imprensa e Propaganda (DIP), tentavam inibir críticas ao governo, ao mesmo tempo em que facilitavam o funcionamento das redações dos jornais que se mostrassem mais condescendentes (CAPELATO, 2012). Precisamente nesse sentido, a cobertura da imprensa sobre a "oficialização" dos esportes universitários tendeu a destacar os aspectos positivos desse processo, que teriam empolgado, conforme se dizia, "todos os setores do país" (PALAVRA... 1941, p. 8). De acordo com o vocabulário empregado pelos jornais da época, os esportes, afinal, eram "poderosos" e "magníficos" veículos de educação moderna, cujos benéficos efeitos não deveriam, por isso mesmo, estar confinados apenas àqueles que quisessem praticá-los (COMENTÁRIOS, 1941, p. 2).

De fato, parecia haver uma aprovação mais ou menos generalizada a medidas que tornassem obrigatória a prática de esportes em universidades, como o faria o decreto-lei 3.617. Essa retórica, que celebrava a "oficialização" das entidades esportivas universitárias, estava inteiramente de acordo com as teleologias do Estado Novo, que tentavam disseminar discursos de uma nova identidade nacional, fortemente orientada por e para o pertencimento patriótico, na qual os jovens seriam peças fundamentais para o aperfeiçoamento da raça brasileira1.

Todavia, apesar da ampla aprovação de que realmente parecia gozar, o processo de "oficialização do esporte universitário" não esteve imune a tensões. Cisões e disputas por vezes dividiam o universo esportivo e estudantil da época. No momento mesmo de fundação da CUBE, em 1939, estudantes-esportistas do Rio de Janeiro e de São Paulo divergiram sobre o local onde deveria funcionar a sede da recém-criada instituição. No final, predominou

1 Para uma análise sobre as teleologias do Estado Novo, ver Parada (2009). 
a vontade dos paulistas de ter em São Paulo a sede da nova instituição. Além disso, houve também desentendimentos a respeito da instituição brasileira que estaria representada junto a Confederação Internacional de Estudantes. Inicialmente, ao que parece, a Casa do Estudante do Brasil, no Rio de Janeiro, era a instituição quem esteve vinculada àquela organização. No entanto, com a fundação da CUBE, um impasse se instituiu a esse respeito. Parece ter havido pressões para a Casa do Estudante reconhecer o monopólio da recém-criada Confederação na representação do Brasil junto a instituições internacionais, o que não aconteceu de início, porém. Apenas com a "pacificação do esporte universitário", a Casa do Estudante do Brasil cedeu e transferiu para a CUBE a filiação junto à Confederação Internacional de Estudantes (PACIFICAÇÃO..., 2 de julho de 1940).

Como resultado de tais divergências, a FAE, do Rio de Janeiro, desvinculou-se da CUBE pouco depois da sua fundação, apesar de ter sido uma de suas fundadoras. Em contrapartida, em abril de 1940, durante mais uma Olimpíada Universitária, que se realizou em São Paulo (era já a terceira), anunciou-se a fundação de uma nova federação de esportes universitários no Rio de Janeiro. A Federação Universitária Carioca de Esportes, como deveria se chamar a nova entidade, criada com apoio dos presidentes da FUPE e da recém-criada CUBE, seria presidida pelo estudante de medicina Neder João Neder e funcionaria como um departamento esportivo do Diretório Central dos Estudantes da Universidade do Brasil, que neste momento era presidido pelo mesmo João Neder (COM A MESMA..., 1940). Ao que parece, a iniciativa não se concretizou. Mesmo assim, uma polêmica instalou-se no meio esportivo e estudantil.

Pouco depois, Virgílio Pires de Sá, estudante de direito que acabara de ser eleito presidente da FAE, escreveu artigo no Jornal do Brasil, no qual defendia a Federação do Rio de Janeiro, ao mesmo tempo em que insinuava acusações a outras instituições estudantis. Os alvos implícitos de suas críticas eram os estudantes e as instituições esportivas de São Paulo. Nas palavras dele, a história da FAE caracterizava-se pelo "labor desinteressado e modesto", "sem auxílio financeiro algum", fez questão de destacar, sempre cumprindo com orgulho sua missão e enfrentando "várias vezes dificuldades bem sérias". Além disso, concluía, os estudantes que dirigiram a FAE sempre teriam nutrido orgulho por nunca terem permitido que a instituição se tornasse, nas palavras dele, uma "entidade de cavação", isto é, um espaço que servisse de oportunidades para ganhos de benefícios diretos ou indiretos. Segundo ele disse:

Todos os seus dirigentes foram sempre verdadeiros estudantes e jamais algum deles se apegou na direção de qualquer cargo para satisfazer interesses pessoais, antes ou depois de formados, ou de terem abandonado as fileiras estudantis. Nunca serviu para apoiar pretensas organizações onde os interesses pessoais de seus dirigentes se delineiam, nitidamente, em detrimento da classe (INJUSTAS..., 1940, p. 12).

Em meio a uma crise institucional que afetava a $\mathrm{FAE}$, que era acusada de inoperante e em pouco mais de um ano alternou três presidentes, o que indicava certa instabilidade, o artigo de Virgílio escancarava tensões latentes entre esportistas universitários. De fato, em comparação com a situação do Rio de Janeiro, a FUPE, cujos quadros foram os principais articuladores também da CUBE, desde a sua fundação contou com muito mais recursos e apoios do governo estadual e até do federal.

Por razões e caminhos que não estão claros, quase imediatamente depois, ainda em abril de 1940, o presidente da CUBE, o acadêmico de São Paulo José Gomes Talarico, 
publicou um artigo no Jornal do Brasil comunicando a reintegração da FAE aos quadros da Confederação, no que foi chamado de "pacificação dos esportes universitários", processo aparentemente delicado, a ponto de envolver pessoalmente as figuras de Getúlio Vargas, Gustavo Capanema e Luiz Aranha (presidente da Confederação Brasileira de Desportos), o que apenas reforça a importância que os esportes universitários tinham para o primeiro escalão do governo, bem como as relações de alguns esportistas-estudantes com esse grupo (PACIFICAÇÃO..., 27 de abril de 1940). Para celebrar o reinício das relações entre as duas entidades, a CUBE ofereceu apoio financeiro para realização de partidas de basquete entre equipes acadêmicas de São Paulo e do Rio de Janeiro contra um selecionado argentino, que aconteceria na inauguração do estádio do Pacaembu.

Com a "pacificação dos esportes universitários", o caminho para a congregação dos esportistas-universitários brasileiros com as prerrogativas governamentais e ideológicas do Estado Novo estava definitivamente pavimentado, o que ajuda a explicar o empenho com que o governo se envolveu com o assunto. Depois disso, eventuais divergências e oposições para a "oficialização" do esporte universitário foram diluídas. Em princípios de novembro de 1940, aproximadamente seis meses depois da "pacificação", um novo Congresso Universitário de Esportes, realizado, dessa vez, na Escola Nacional de Música, no Rio de Janeiro, com o propósito de iniciar a organização de mais uma Olimpíada Universitária Brasileira, que se planejava acontecer no Rio de Janeiro, discutiu também o "anteprojeto de regulamentação do esporte universitário", que, conforme noticiou um jornal de São Paulo, deveria estar "perfeitamente organizado dentro das diretrizes traçadas pelo governo" (DE TUDO UM POUCO, 1940, p. 8).

Apesar das intenções, aquela Olimpíada Universitária Brasileira acabou se realizando novamente em São Paulo, em junho de 1941. ${ }^{2}$ Em setembro daquele ano, a "oficialização dos esportes universitários" finalmente se tornaria realidade, com a promulgação do decreto-lei no 3.617. Com isso, o elemento fundamental para a organização inicial dos esportes universitários no Brasil se transformou muito significativamente. Possibilidades de profissionalização do esporte universitário, que eram ventiladas por algumas pessoas na época (cf. RODRIGUES, 1941), foram definitivamente deixadas de lado, uma vez que a sua "oficialização" impunha o amadorismo como condição. A sede da antiga CUBE, já renomeada como CBDU, fora transferida de São Paulo para o Rio de Janeiro, mais próximo da sede do poder político federal, mas mais distante do principal centro esportivo universitário da época. $O$ associativismo civil manejado pelos próprios estudantes deu lugar a uma organização inteiramente subordinada ao Estado, que the financiava e the ditava as diretrizes. Depois disso, as organizações esportivas universitárias passaram tão somente a representar valores e aspirações políticas do Estado Novo - que durou até 1945.

\section{CONSIDERAÇÕES FINAIS}

Há certo consenso historiográfico no Brasil de que iniciativas do poder público teriam sido fundamentais para a organização dos esportes no país depois de 1930 (BUENO, 2009; COUTO, 2014; DRUMOND, 2014; LINHARES, 1996; 2009; MANHÃES, 1986). Essa é uma conclusão geral acertada e nossa análise a confirma em grande medida. Em sentido ligeiramente diferente, porém, divergindo parcialmente deste consenso, nossa interpretação

2 Foi quando se adotou o nome "Jogos Universitários Brasileiros", aplicado, inclusive, para as competições realizadas anteriormente e utilizado até os dias de hoje. 
aqui, tomando o esporte universitário como exemplo, também aponta para outros agentes que não apenas o Estado nesse processo. Segundo nossa interpretação, o associativismo civil protagonizado pelos próprios estudantes foi um dos principais fatores para o desenvolvimento inicial do esporte universitário no Brasil, ao menos até 1941.

O início da prática esportiva universitária no Brasil, ao longo de quase quatro décadas, ocorreu sem a intervenção direta do Estado, embora o poder público tenha oferecido apoio financeiro eventual para a realização de algumas competições esportivas entre estudantes. De modo geral, no entanto, o esporte universitário era arranjado por iniciativa e por meio da organização dos próprios estudantes. Por todo esse período, o associativismo estudantil esteve mesmo no centro da consolidação do esporte universitário no Brasil. A realização de competições, a criação de federações estaduais, bem como a gestão dessas entidades, que não contavam com apoio financeiro ou administrativo regular de governos, foram única e exclusivamente iniciativa dos próprios estudantes. Eram os estudantes, em suma, que atuavam como os principais protagonistas do esporte universitário. Mesmo o processo de envolvimento do Estado com o esporte universitário entre as décadas de 1930 e 1940 foi em grande medida agenciado pelos estudantes. Fosse por força de convicções ideológicas ou por mera conveniência oportunista, foram os estudantes que dirigiram associações esportivas universitárias, que reivindicaram e trabalharam deliberadamente para obter o apoio estatal em favor de suas organizações. Em última instância, sem o protagonismo estudantil, o esporte universitário não teria se desenvolvido a ponto de ser útil e relevante para a agenda política do governo. Nesse sentido, não podemos limitar a análise histórica do esporte universitário brasileiro apenas ao ponto de vista dos agentes estatais, sob o risco de silenciar outros atores que foram fundamentais para o desenvolvimento dessas práticas.

Todavia, com tudo isso, também não seria adequado simplesmente negar a participação e a influência do poder governamental sobre o esporte universitário, especialmente depois de 1937, quando a escalada centralizadora e autoritária do governo de Vargas, iniciado em 1930, atinge novo patamar com o Estado Novo. Desse momento em diante, um esforço governamental para utilização política dos esportes em favor dos objetivos programáticos e ideológicos do Estado ganha contornos mais claros e enfáticos. No entanto, não houvesse aí toda uma mobilização prévia e um aparato institucional já disponível, dificilmente essa apropriação teria sido possível. Na verdade, não fosse a atuação voluntária de estudantes em favor dos esportes nas instituições de ensino superior durante os anos anteriores a esse processo, não haveria o que ser apropriado.

Nesse sentido, a emergência histórica dos esportes universitários no Brasil não ocorreu repentinamente. Ao contrário, tratou-se do lento acúmulo de experiências ao longo de um período que se estendeu por décadas e que acabou por sedimentar a própria noção de esporte universitário. Nesse longo processo, o associativismo civil foi um fator fundamental. Estudantes e suas associações não foram agentes passivos diante de poderes governamentais absolutos. A vontade política do Estado não foi o único dínamo para o desenvolvimento histórico do esporte universitário no Brasil, em que pese sua importância, mais notável, mesmo assim, apenas a partir de meados da década de 1930. 


\section{REFERÊNCIAS}

A 1‥ OLYMPIADA Universitária será realizada em fins de abril próximo. Correio de São Paulo, 12 dez. 1934, p. 4.

ATLETISMO. Diário de Pernambuco, 21 out. 1934, p. 6.

BAILE UNIVERSITÁRIO carnavalesco. Correio Paulistano, 22 jan.1936, p. 4.

BOMENY, Helena. Três decretos e um ministério: a propósito da educação no Estado Novo. In: PANDOLFI, Dulce (org.). Repensando o Estado Novo. Rio de Janeiro: Editora da FGV, 1999. p.137-166.

BRASIL. Decreto-Lei n. 3.199, 14 de abril de 1941. Estabelece as bases de organização dos desportos em todo o país. Disponível em: http://www6.senado.gov.br/legislacao/ListaPublicacoes. action?id=152593. Acesso em: 20 mar. 2019.

O BRASIL AUSENTE dos Jogos Universitários Internacionaes. O Dia Esportivo, 5 jul. 1935. p. 6.

BRASIL. Recenseamento geral do Brasil. Rio de Janeiro: Instituto Brasileiro de Geografia e Estatística 1950. v. 2.

BUENO, Luciano. Políticas públicas do esporte no Brasil: razões para o predomínio do alto rendimento. 2008. 296f. Tese (Doutorado em Administração) - Fundação Getulio Vargas, São Paulo, 2008.

CAPELATO, Maria Helena. O Estado Novo: o que trouxe de novo? In: FERREIRA, Jorge; DELGADO, Lucilia de Almeida Neves (orgs.). O Brasil republicano: o tempo do nacionalestatismo. Rio de Janeiro: Civilização Brasileira. 2012. v. 2, p. 107-144.

COLLEGAS DE TODO BRASIL, S. Paulo vos espera de braços abertos. Correio Paulistano, 24 out. 1939, p. 8.

COM A MESMA solenidade da abertura encerra-se hoje a II Olympiada Universitaria Brasileira. Correio Paulistano, 07 abril 1940, p. 14-15.

COMENTÁRIOS. O Dia Esportivo, 1 out. 1941, p. 2.

COMO SERÁ resolvida a pendência do Campo do São Paulo? Correio de São Paulo, 26 jun. 1935, p. 5.

CONSELHO NACIONAL DE ESTUDANTES. Jornal do Brasil, 13 ago. 1937, p. 6.

COUTO, Euclides de Freitas. Da ditadura à ditadura: uma história política do futebol brasileiro (1930-1978). Niterói: Editora da UFF, 2014.

DE TUDO UM POUCO. Correio Paulistano, 6 nov. 1940, p. 8.

DRUMOND, Maurício. Estado novo e esporte: a política e o esporte em Getúlio Vargas e Oliveira Salazar (1930-1945). Rio de Janeiro: 7 Letras, 2014.

DULLES, John. A Faculdade de Direito de São Paulo e a resistência anti-Vargas: 19381945. Rio de Janeiro; São Paulo: Nova Fronteira - EDUSP, 1984. 
O ESPORTE UNIVERSITÁRIO. Diário de Pernambuco, 23 out. 1934, p. 6.

ESPORTE UNIVERSITÁRIO. O Estado, 24 abril 1937, p. 5.

A FEDERAÇÃO Universitária Paulista de Esportes homenageia o senhor secretário da Educação. Correio de São Paulo, 25 maio 1935, p. 3.

OS FLUMINENSES são campeões universitários de natação. Correio de São Paulo, 2 maio 1935 , p. 5.

HORTA, José Silvério Baía. O hino, o sermão e a ordem do dia: regime autoritário e a educação no Brasil (1930-1945). 2. ed. Campinas: Autores Associados; 2012.

INJUSTAS as acusações feitas à Federação Atlética de Estudantes. Jornal do Brasil, 18 abril 1940, p. 12.

LINHARES, Meily Assbú. A escola e o esporte: uma história de práticas culturais. São Paulo: Cortez, 2009.

LINHARES, Meily Assbú. A trajetória política do esporte no Brasil: interesses envolvidos, setores excluídos. 1996. 242f. Dissertação (Mestrado em Ciência Política) - Universidade Federal de Minas Gerais, Belo Horizonte, 1996.

MAIS UMA SESSÃO semanal da Federação Universitária Paulista de Esportes. Correio de São Paulo, 4 jul. 1935, p. 3.

MANGAN, James Anthony. Athleticism in the Victorian and Edwardian Public School: the Emergence and Consolidation of an Educational ideology. Cambridge: Cambridge University, 1981.

MANHÃES, Eduardo Dias. Política de esportes no Brasil. Rio de Janeiro: Graal, 1986.

A MOCIDADE UNIVERSITÁRIA e sua nova organização esportiva. A Manhã, 19 set. 1941, p. 14 O'HANLON, Timothy. School Sports as Social Training: The Case of Athletics and the Crisis of World War I. Journal of Sport History, v. 9, n. 1, p. 5-29, 1982.

PACIFICAÇÃO dos esportes universitários. Jornal do Brasil, 27 abril 1940, p. 12.

PACIFICAÇÃO dos esportes universitários. Jornal do Brasil, 2 jul. 1940, p. 12.

PALAVRA das mais autorizadas como o general Newton Cavalcanti falou sobre 0 amparo do governo ao esporte universitário. 0 Jornal, 20 set. 1941, p. 8.

PARADA, Maurício. Educando corpos e criando a nação: cerimônias cívicas e práticas disciplinares no Estado Novo. Rio de Janeiro: Apicuri, 2009.

OS PAULISTAS são campeões olímpicos universitários de futebol. Correio de São Paulo, 2 maio 1935, p. 4.

RODRIGUES, Augusto. O esporte universitário no Brasil e no mundo. Diretrizes, 16 out. 1941, p. 2.

SANTOS NETO, José Moraes dos. Visão do jogo: primórdios do futebol no Brasil. São Paulo: 
SERÁ PRECISO licença para o universitário disputar campeonato em outras entidades. Correio Paulistano, 17 nov. 1940, p. 15.

SOB O PATROCÍNIO do Secretário da Agricultura, o esporte universitário paulista será representado nos jogos de Minas Geraes. Correio Paulistano, 6 jul. 1938, p. 8.

STAREPRAVO, Fernando Augusto. 0 esporte universitário paranaense e sua relação com o poder público. 2006.167f. Dissertação (Mestrado em Educação Física) - Universidade Federal do Paraná, Curitiba, 2006.

STAREPRAVO, Fernando Augusto et al. Esporte universitário brasileiro: uma leitura a partir de suas relações com o Estado. Revista Brasileira de Ciências do Esporte, v. 31, n. 3, p. 131148, maio 2010.

UM GRANDE torneio colegial de basket-ball promovido pela Federação Atlética de Estudantes. Jornal do Brasil, 8 ago. 1933, p. 14.

UMA ASPIRAÇÃO esportiva dos universitários brasileiros. Correio Paulistano, 27 ago. 1938, p. 15.

\section{Apoio:}

O presente trabalho foi realizado com apoio da Coordenação de Aperfeiçoamento de Pessoal de Nível Superior -Brasil (CAPES) - Código de Financiamento 001. This study was financed in part by the Coordenaç̧ão de Aperfeiçoamento de Pessoal de Nível Superior - Brasil (CAPES) -Finance Code 001 